\title{
Dos comunidades formativas en el valle medio de Lurín: una comparación de los sitios de Anchucaya y Chillaco
}

\author{
Two formative communities in the middle valley of Lurín: a \\ comparison of the sites of Anchucaya and Chillaco
}

\author{
Christopher Milan \\ https://orcid.org/oooo-0002-2646-1863 \\ DePaul University \\ chris.milan235@gmail.com
}

\section{RESUMEN}

Anchucaya y Chillaco son dos aldeas del Periodo Inicial (1800 - 800 a. C.) que ocupaban el valle medio de Lurín, en la costa central del Perú. Aunque hay varias similitudes entre los dos sitios, las diferencias indican que las aldeas tenían dos poblaciones distintas. Se revelan como los desarrollos de esta época han afectado asentamientos rurales y las maneras en que las comunidades pueden expresar su autonomía.

Palabras clave: Periodo Inicial, costa central, Lurín, aldeas.

\section{ABSTRACT}

Anchucaya and Chillaco are two villages from the Initial Period (1800 - 800 BC) that occupied the middle valley of Lurín, on the central coast of Peru. Although there are several similarities between the two sites, the differences indicate that the villages had two distinct populations. It reveals how the developments of this era have affected rural settlements and the ways in which communities can express their autonomy.

Keywords: Initial Period, central coast, Lurin, villages. 


\section{INTRODUCCIÓN}

Los sitios arqueológicos de Anchucaya y Chillaco son una pareja en oposición. Es decir que las similitudes entre los sitios revelan sus diferencias. Ambos sitios son aldeas que se ocuparon durante el Periodo Inicial (1800 - 800 a. C.). Ambos se ubican en la sección medio del valle Lurín en la costa central del Perú, y tuvieron lazos al centro cívico-ceremonial de Malpaso. Pero los materiales recolectados de los sitios - la cerámica, arquitectura residencial, bienes rituales, etc. - son tan únicos que indican que se ocuparon por dos poblaciones distintas.

El Periodo Inicial se caracteriza por una serie de desarrollos que contribuyeron a la aparición de la sociedad compleja en la costa central del Perú (Burger 2009). La introducción de nuevas tecnologías que incluye cerámica y canales de riego facilitaron la construcción de asentamientos interiores permanentes y arquitectura monumental. Anchucaya fue uno de los primeros asentamientos establecidos en el valle medio de Lurín. Entonces se informa sobre cómo las primeras poblaciones migraron a la región y el rol de los templos en planta de $\langle U\rangle$, como Malpaso, tiene. Mientras Chillaco se ocupa al fin del Periodo Inicial y fue parte de una red más expansiva que conectaron templos y aldeas que se ubican en la costa del Pacífico, el interior del valle, y la sierra adyacente. En parte, las diferencias entre los sitios son representativos de los cambios sociales más grandes que ocurrieron en la región.

Aunque ambas aldeas tuvieron una relación con Malpaso, el centro cívico-ceremonial más cercano, sería un error considerarlos como asentamientos subordinados. Ellos tenían bastante autonomía política y económica. Producían sus propios ceramios, realizaban rituales en las mismas aldeas, y participaban en una red de intercambio con otras aldeas y templos. Investigaciones recientes sobre pueblos y aldeas han revelado que estas comunidades rurales expresaban bastante independencia. Anchucaya y Chillaco se formaron como comunidades distintas con sus propias identidades, y eso se ve en sus culturas materiales.

En parte, sus identidades distintas de los dos sitios son por su ambiente. Ambos se ubican en la chaupiyunga, una zona climática entre la costa del Pacífico y la sierra Andina. La chaupiyunga no solo es un clima intermedio; Frank Salomon y Susan Grosboll (2011, p. 23) la describen como una frontera cultural donde las poblaciones de zonas diferentes interactuaban e intercambiaban ideas. Al observar las diferencias en los materiales culturales es posible entender como Anchucaya y Chillaco representan dos poblaciones separadas, una de la costa y otra de la sierra. También por las similitudes entre los dos se revelan los mecanismos que permitió que dos poblaciones distintas se formen y se afilien con un templo temprano. 


\section{EL PERIODO INICIAL EN EL VALLE LURÍN}

El valle Lurín es el más pequeño de los cuatro - con los valles de Chancay, Chillón, y Rímac - que forman la costa central del Perú (figura 1). Tiene un largo de alrededor de 70 kilómetros de la confluencia de sus tributarios principales hasta el océano. Como otros valles costales, el valle Lurín se puede dividir en zonas climáticas por su elevación (Pulgar Vidal, 1981). La chala se empieza por el nivel del mar y extiende hasta una elevación de alrededor 600 metros sobre nivel del mar (m s. n. m.). Es una llanura aluvial amplia que recibe poca lluvia durante los meses de invierno, pero la mayoría del agua viene del río y puquios, fuentes naturales de agua. En el valle Lurín, el tercero más bajo, hasta el sitio de Quebrada San Francisco, se considera chala. La chaupiyunga se empieza al punto donde el valle se reduce drásticamente. También la inclinación del valle se vuelve más exagerada. Esta topografía crea un clima árido, con menos que $70 \mathrm{~mm}$ de precipitación anual, sin variación estacional. El clima es ideal para el cultivo de plantas de alto valor como ají y coca. La geografía de la chaupiyunga restringe el área de tierra agrícola, y por eso ha sido una zona contestada por varios grupos que querían explotar los recursos naturales (Salomon et al, 2011). La sierra baja, que se llama la zona quechua, se empieza por una elevación alrededor de 1800 m s. n. m. En el valle Lurín, la zona quechua se llama Huarochirí.

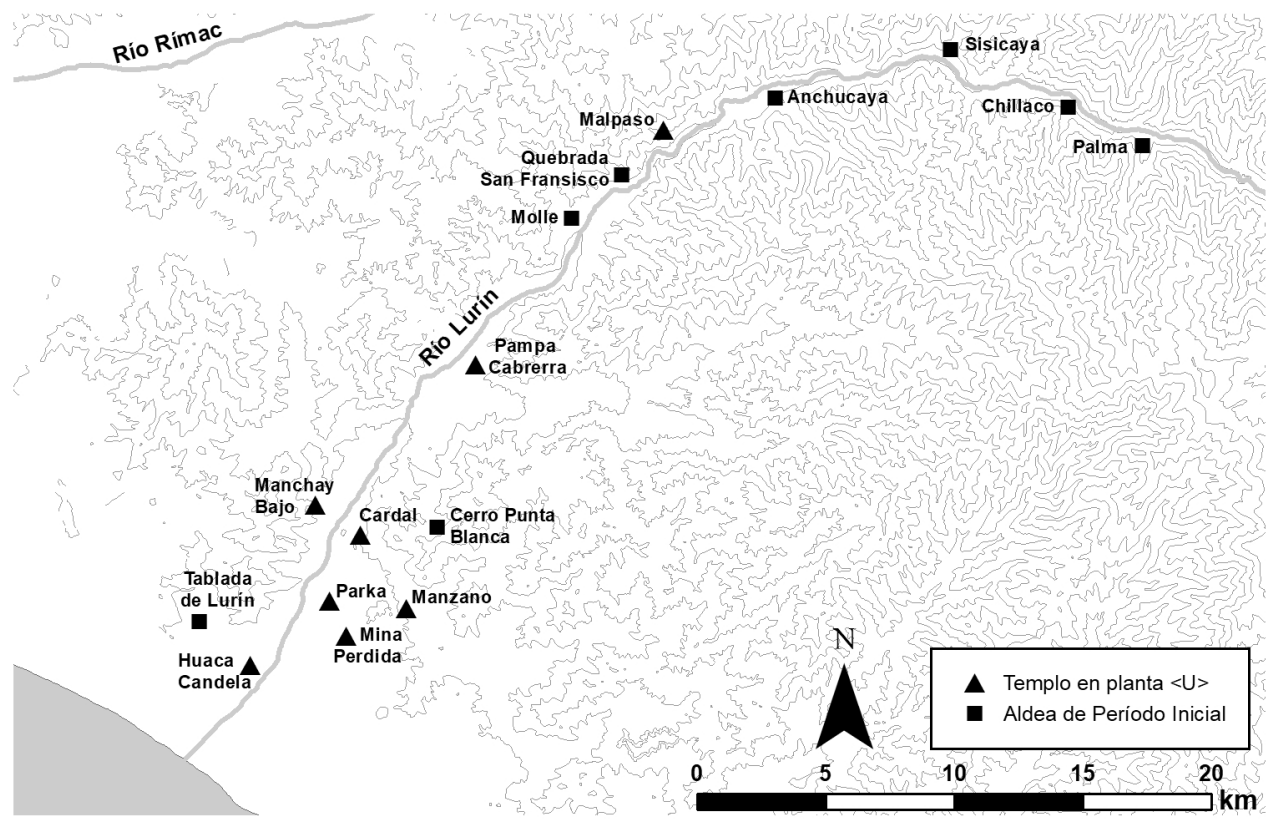

Figura 1. Mapa topográfico del valle de Lurín con sitios del Periodo Inicial. 
Al principio del Periodo Inicial la población de la costa central vivía mayormente en aldeas pescadores por la costa del Pacífico como en los sitios de Ancón y Paloma. Los habitantes de estas aldeas explotaban recursos marinos todo el año que se aumentaban con lo que cazaban y recolectaban en el interior del valle por campos estacionales (Burger, 1992, p. 62). La introducción de nuevas tecnologías como agricultura, canales de riego, y cerámica permitieron que la gente establecer asentamientos permanentes en el interior del valle. Porque la chala y chaupiyunga no reciben suficiente lluvia, los canales de riego son esenciales para sostener agricultura en estas zonas. Mientras la población en el interior del valle se crecía los primeros sitios monumentales, los templos en planta de $\langle\mathrm{U}\rangle$, fueron construidos en la costa central.

Carlos Williams (1980) fue el primero en identificar los templos en planta de $\langle\mathrm{U}\rangle$ como una tradición arquitectónica única a la costa central del Perú. Un templo en planta de $<U>$ consiste en una pirámide o montículo principal con dos brazos que encierran una plaza principal (figura 2). Normalmente un brazo es más grande que el otro. También un brazo es conectado al montículo principal mientras el otro está solo. Hay bastante espacio para variación para la organización de un templo entre esta tradición. Burger y Salazar (2008) expanden de las obras de Williams y dicen que el templo en planta de $<\mathrm{U}>$ es la forma de arquitectura monumental exclusiva para la costa central del Perú en este periodo. Ellos notan también que los templos en planta de $<U>$ comparten una iconografía y prácticas religiosas. Por eso, se llama la tradición arquitectónica la Cultura Manchay.

En el valle Lurín hay ocho templos en planta de $\langle\mathrm{U}>$. El más antiguo y grande es Mina Perdida, que se empezó construir alrededor de 2000 a. C. En los siglos siguientes otros templos en planta de $<\mathrm{U}>$ estaban construidos: Cardal, Huaca Candela, Manchay Bajo, Manzano, Pampa Cabrerra, Parka, and Malpaso. Muchos de los templos se ubican en proximidad a otros. Por ejemplo, Cardal, Manzano, Mina Perdida, y Parka están entre 4 kilómetros de cada uno. A pesar de esta proximidad Mina Perdida no era la capital de un estado que dominaba otros templos en el valle. Se parece que cada templo representa una comunidad autónoma. Los templos expresaron sus identidades distintas por su cultura material. Aunque cada templo se conformaba a la tradición de la cultura Manchay, hubo variación en que brazo se conecta con el montículo principal, construcciones sobre los montículos y otras adicciones (Williams, 1980). Aún más, la cerámica varía entre los templos, y por eso no es posible designar un estilo de cerámica a la Cultura Manchay. También, Jorge Silva (1998, p. 264) observa que la cerámica producida por los templos del valle Chillón varía bastante. Pero, Silva nota que la cerámica entre dos templos más cercanos es similar.

Malpaso es único templo en planta de $<U>$ en el valle medio de Lurín. Se presenta como un ejemplo en como cada templo es distinto (Milan, 2014). Se ubica en la 


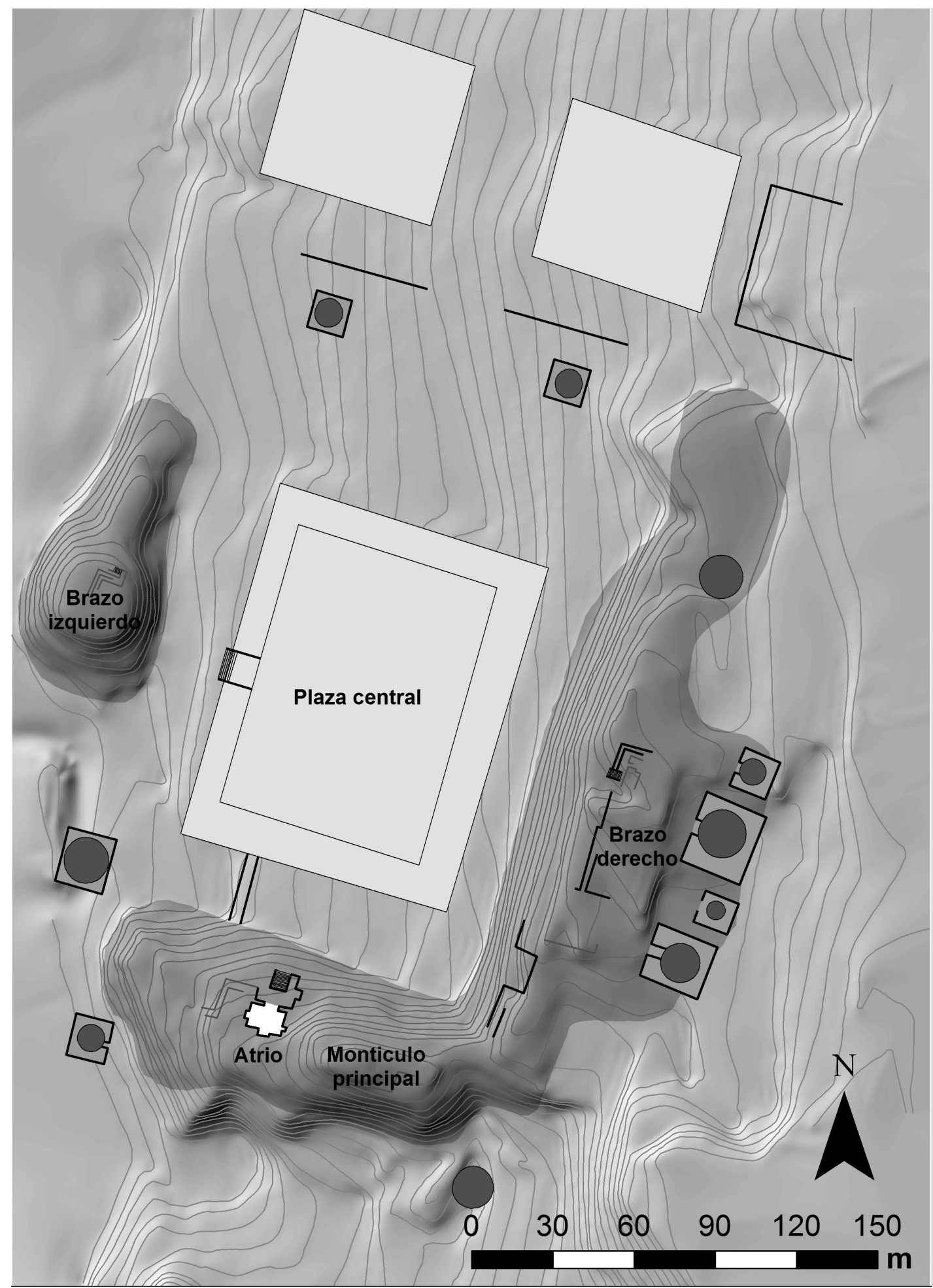

Figura 2. Mapa del sitio de Cardal. 
entrada de Quebrada San Vicente, 36 kilómetros de la costa. En este punto el valle Lurín es el más restringido con una anchura de no más de 100 metros. Por falta de espacio Malpaso es más pequeño que los otros templos en el valle; tiene un área de una hectárea, y su montículo principal y brazo izquierdo tienen una altura de justo a 10 metros. Para comparación, Cardal, en el valle bajo, tiene un área de más que 11 hectáreas y su montículo principal tiene una altura de más que 20 metros. Como en templo en planta de $\langle U\rangle$, Malpaso conforma a la tradición de la Cultura Manchay (figura 3). El brazo izquierdo está conectado al montículo principal, y también el brazo izquierdo es más grande que el derecho. Pero se nota que el brazo derecho está en un estado de mala conservación. La plaza tiene dos características distintas - una depresión circular que está limpio de derrito y un muro que corre de brazo a brazo.

La ocupación de Malpaso se puede dividir en tres fases: el Fase Río (1600 - 1300 a. C.), el Fase Liza (1300 - 1000 a. C.) y el Fase Milagro (1000 - 500 a. C.). Las primeras construcciones en el templo estaban hechas entre 1600 y 1550 a. C., que lo pone contemporáneo con otros templos en el valle bajo de Lurín (Tabla 1). Como estos templos, Malpaso se sometía a una serie de renovaciones en los siglos siguientes. Des-

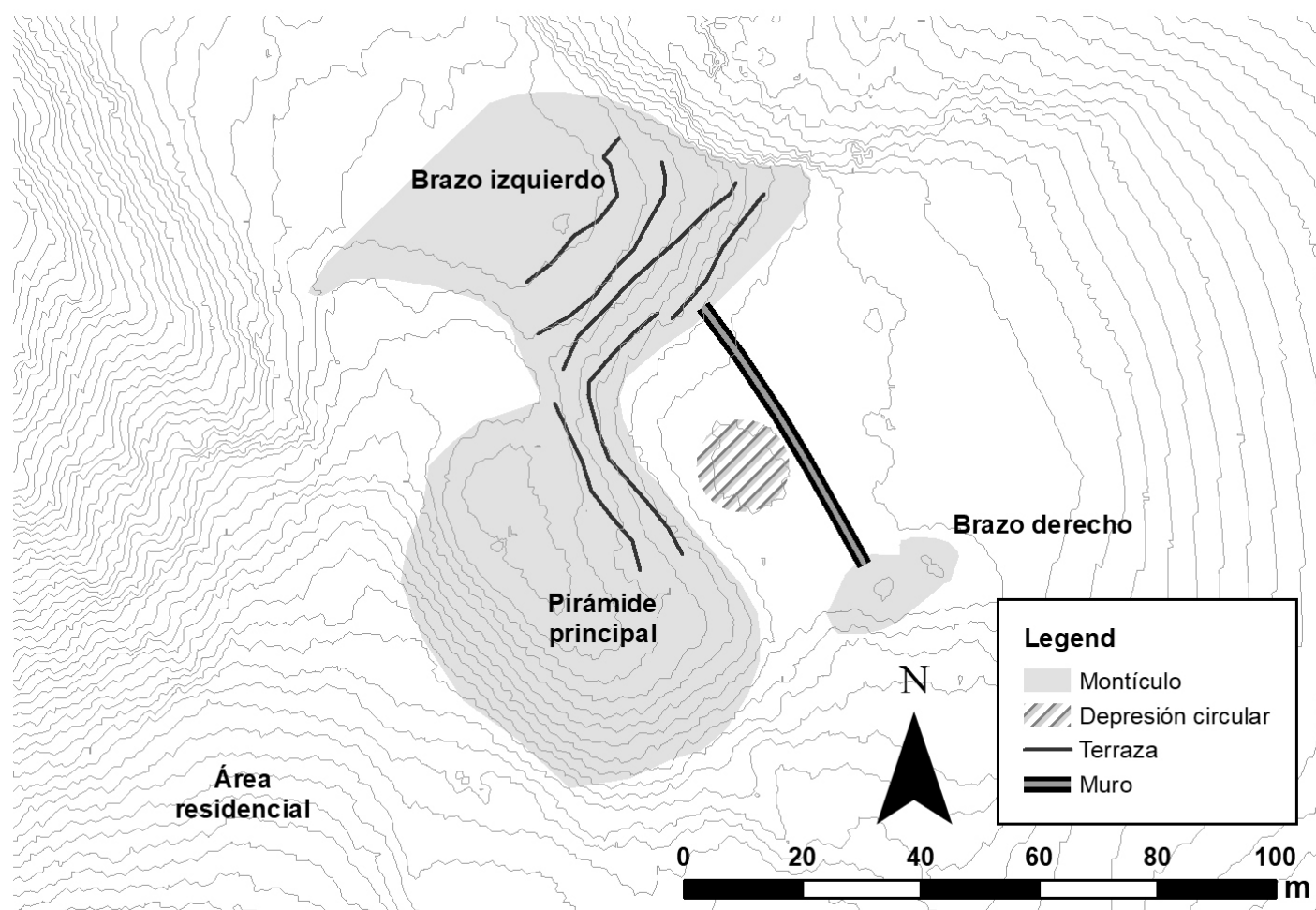
Figura 3. Mapa del sitio de Malpaso. 
Tabla 1: Lista de muestras radiocarbónicos recolectados de los sitios en el valle medio de Lurín.

\begin{tabular}{|c|c|c|c|c|}
\hline $\begin{array}{l}\text { Muestra de } \\
\text { carbón }\end{array}$ & Sitio & Contexto & Fecha sin calibración & Fecha calibrado \\
\hline $\begin{array}{l}\text { PAV- } \\
\text { MEL-1-RBo11 }\end{array}$ & Malpaso & $\begin{array}{l}\text { Unidad I, encima } \\
\text { de deposito de } \\
\text { conchas }\end{array}$ & $3164 \mathrm{BP} \pm 27$ & $1493-1313 \mathrm{BC}$ \\
\hline $\begin{array}{l}\text { PAV- } \\
\text { MEL-1-RBo12 }\end{array}$ & Malpaso & $\begin{array}{l}\text { Unidad I, en un } \\
\text { deposito de con- } \\
\text { chas }\end{array}$ & $3295 \mathrm{BP} \pm 21$ & $1608-1437 \mathrm{BC}$ \\
\hline $\begin{array}{l}\text { PAV- } \\
\text { MEL-1-RBo14 }\end{array}$ & Malpaso & $\begin{array}{l}\text { Unidad I, fondo } \\
\text { de deposito de } \\
\text { conchas }\end{array}$ & $3343 \mathrm{BP} \pm 33$ & $1679-1459 \mathrm{BC}$ \\
\hline $\begin{array}{l}\text { PAV- } \\
\text { MEL-1-RBo17 }\end{array}$ & Malpaso & $\begin{array}{l}\text { Unidad I, debajo } \\
\text { de Piso } 2\end{array}$ & $3180 \mathrm{BP} \pm 27$ & $1446-1271 \mathrm{BC}$ \\
\hline $\begin{array}{l}\text { PAV- } \\
\text { MEL-1-RBo18 }\end{array}$ & Malpaso & $\begin{array}{l}\text { Unidad I, debajo } \\
\text { de Piso } 4\end{array}$ & $3216 \mathrm{BP} \pm 29$ & $1506-1321 \mathrm{BC}$ \\
\hline $\begin{array}{l}\text { PAV- } \\
\text { MEL-1-RBo59 }\end{array}$ & Malpaso & $\begin{array}{l}\text { Unidad IV, Capa F, } \\
\text { debajo de Piso } 2\end{array}$ & $3128 \mathrm{BP} \pm 31$ & $1428-1221 \mathrm{BC}$ \\
\hline $\begin{array}{l}\text { PAV- } \\
\text { MEL-1-RBo60 }\end{array}$ & Malpaso & $\begin{array}{l}\text { Unidad I, Capa J, } \\
\text { debajo de Piso } 4\end{array}$ & $3215 \mathrm{BP} \pm 30$ & $1506-1321 \mathrm{BC}$ \\
\hline PAVMEL-2-RBo8 & Anchucaya & Unidad IV, Capa C & $3172 \mathrm{BP} \pm 31$ & 1493-1294 BC \\
\hline $\begin{array}{l}\text { PAV- } \\
\text { MEL-2-RBo14 }\end{array}$ & Anchucaya & Unidad IV, Capa D & $3280 \mathrm{BP} \pm 30$ & $1608-1422 \mathrm{BC}$ \\
\hline PAVMEL-5-RBo8 & Chillaco & Unidad VII, Capa B & $2737 \mathrm{BP} \pm 30$ & 904-798 BC \\
\hline
\end{tabular}

pués de 1300 a. C. el montículo principal y el brazo izquierdo estaban levantado más que un metro, marcando un cambio significante al templo. Como en la fase anterior, durante los tres siglos que siguen se realizaban más renovaciones a la arquitectura monumental. La ocupación terminal de Malpaso no está bien definida. Todos los contextos después de 1000 a. C. estaban dañados por un derrumbe de piedras que cubrieron el brazo izquierdo y la plaza central. Los materiales recuperados de estos contextos indican que el sitio estaba ocupado después de 800 a. C. Pero no se sabe la fecha cuando el sitio estaba abandonado.

Los materiales de Malpaso demuestra cómo se desarrolló durante el tiempo de su ocupación y como se interactuaban con otros sitios en el valle Lurín. La cerámica es característica de que se encuentra en otros templos en planta de $<U>$. Las vasijas típicas son ollas sin cuello y cuencos con paredes rectas y bordes cónicos (figuras 4-1 a 4-5). Como en otros templos, la cerámica decorada es distinta. Las técnicas 
para decoración más típicas son diseños sencillos incisos y puntación zonal, donde líneas incisas por la superficie de la vasija encierran áreas cubiertas con puntaciones hecho por una aguja (figuras 4-5, 4-6, 4-7, y 4-9). La cerámica decorada también sirve como evidencia de intercambio con otros templos en el valle bajo de Lurín. Hay ejemplos de fragmentos con diseños intrínsecos incisos similares a que se encuentra en Cardal y fragmentos con pintura bícroma típica de Manchay Bajo (Fajardo 1996 y Thorne 1999). Intercambio entre el valle bajo y la chaupiyunga aumentaban con el tiempo. Mas que la cerámica, Malpaso importaba cantidades de recursos marinos, en particular moluscos como Mesodesma donacium y Choromytilus chorus, más grandes. Contextos de la Fase Milagro contenían más que 40 kilogramos de conchas del mar. La cerámica indica que Malpaso también tenía contacto con otras regiones del Perú durante el Fase Milagro. Hay fragmentos decorados con el círculo con puntos y pintura post-cocción, diseños asociados con culturas que participaban en el culto Chavín (figura 4-8 y 4-9).

Los materiales de Malpaso son evidencia de una red de intercambios robusta que conectaban los templos en planta de $<U>$ del valle Lurín y más allá. Se levanta preguntas del rol de asentamientos rurales en la sociedad del Periodo Inicial. Tradicionalmente arqueólogos presumen que los centros cívico-ceremoniales tempranos ejercían un poder coactivo sobre asentamientos cercanos, como pueblos y aldeas, para forzarles a someterse a la autoridad de las élites. Este modelo presume una relación entre los centros y aldeas que es unilateral, y que las aldeas existen a apoyar el centro (Stanish, 1999, p. 17). Pero Burger (2009, p. 31) y otros no encuentran evidencia de un poder coactivo en la Cultura Manchay. No hay evidencia de una élite que dominaba la región de los templos en planta de $\langle U\rangle$, tampoco había una jerarquía de los sitios donde el templo más grande servía como la capital regional. Mientras hay bastante evidencia de interacción entre los templos, nadie habla de un sistema político de pares; es porque es difícil imaginar los templos representando entidades políticas cuando no se entiende la manera ni límite de su poder (Patterson, 1985).

Por eso Anchucaya y Chillaco presentan unas perspectivas nuevas sobre el Periodo Inicial. Las ocupaciones de estos dos sitios demuestra cómo la gente que vivían en asentamientos rurales estaba afectada por la aparición y desarrollo de los templos en planta de $\langle U\rangle$. Los sitios presentan como sus poblaciones beneficiaron de participar en el intercambio entre los sitios de la Cultura Manchay y a qué punto se afiliaban con los templos. El límite del poder de los templos en planta de $<U>$ sale más definida, igual como la autonomía de comunidades rurales de la misma época.

\section{Anchucaya}

Anchucaya se ubica en una quebrada del mismo nombre que es 7 kilómetros al noreste de Malpaso y por el otro lado del río. Tiene una elevación de $800 \mathrm{~m} \mathrm{s.} \mathrm{n.} \mathrm{m.}$ La ocupación del sitio es larga y la tafonomía del sitio es complicado (Milan, 2019). 
Fig 4-1

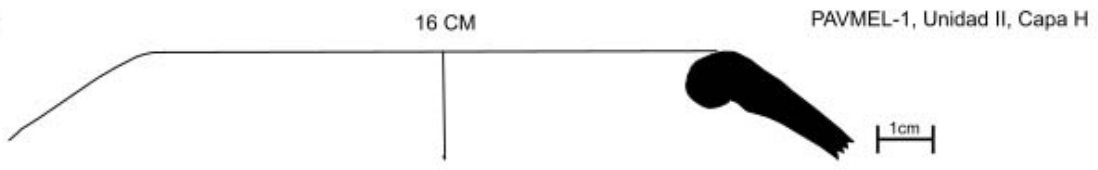

Fig. 4-2

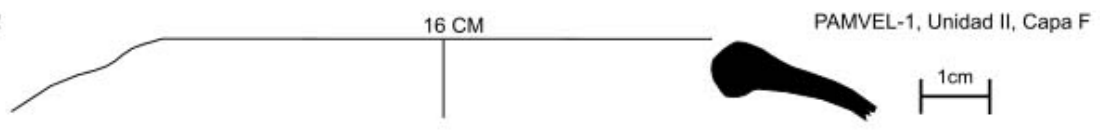

Fig. 4-3

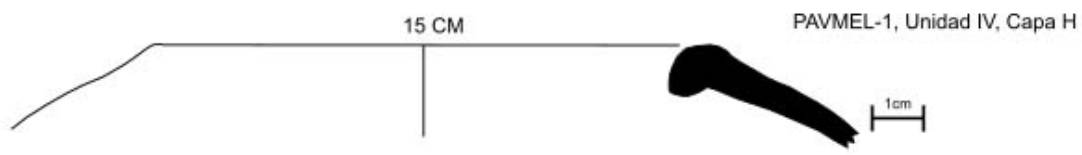

Fig. 4-4

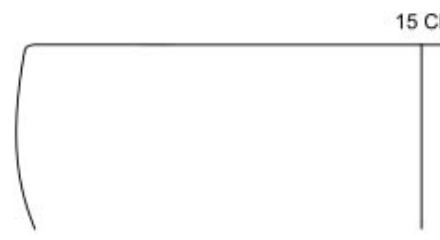

PAMVEL-1, Unidad IV, Capa E

Fig. 4-5

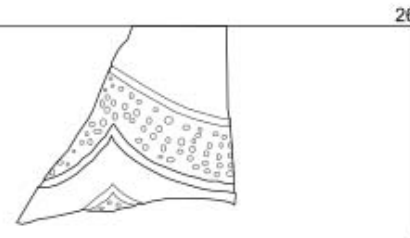

$26 \mathrm{CM}$
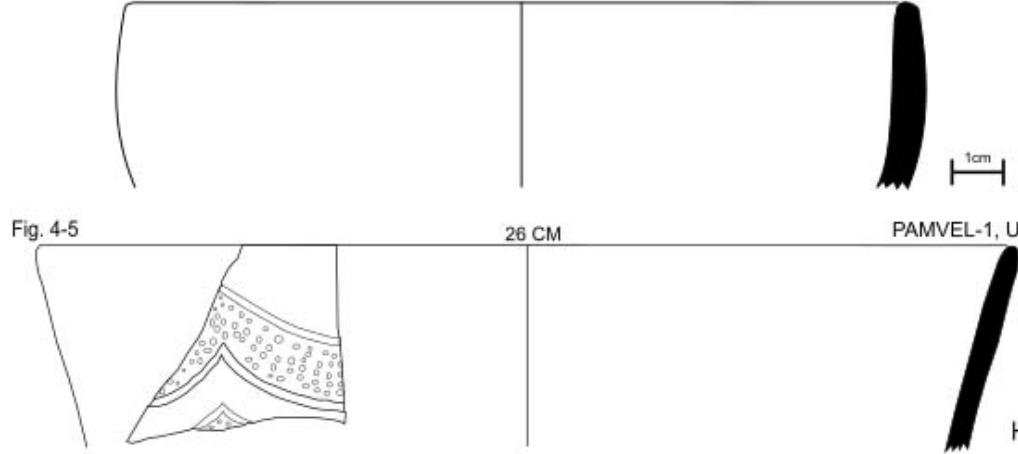

Fig. 4-6

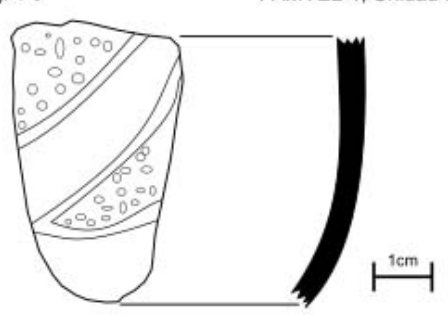

Fig. 4-8

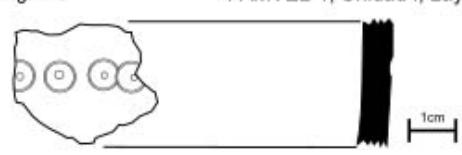

PAMVEL-1, Unidad I, Capa F
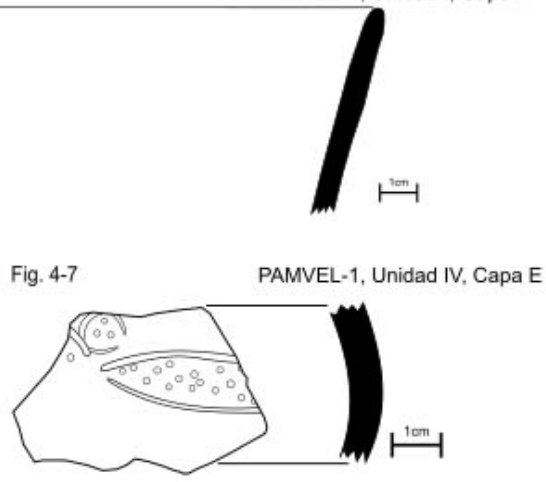

Fig. 4-9 PAMVEL-1, Unidad IV, Capa E

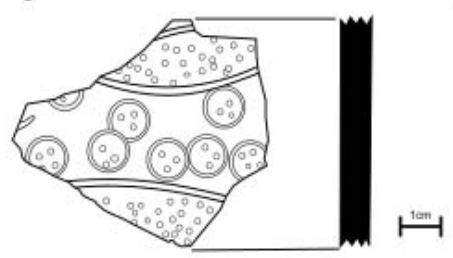

Figura 4. Dibujos de cerámica de Malpaso. 
La ocupación original se fecha a entre 1500 y 1200 a. C. Después de su abandono, la gente reocupó el sitio durante el Periodo Intermedio Temprano (200 a. C. - 600 d. C.) con la construcción de plataformas residenciales en la ladera de la quebrada (Salomon et al 2011). Entre el Periodo Intermedio Tardío (900 - 1450 d. C.) y Horizonte Tardío (1450 - 1532 d. C.) el sitio era reocupado otra vez. La gente creó una serie de terrazas agrícolas que afectaban los contextos anteriores. En tiempos modernos el sitio está entre la comunidad Sierra Morena, que consiste en unas casas de campos grandes. Como parte de la construcción de Sierra Morena, Anchucaya y dos otros sitios, Antivalles y Chontay, están designados zonas intangibles.

Anchucaya es más conocido por tener un montículo que consideraban un templo en planta de $<U>$ (Mesía 2000; Salomon et al 2011). Excavaciones en 2010 indican que el montículo fue construido durante el Periodo Intermedio Tardío o Horizonte Tardío. El plano del montículo no se conforma a la tradición de la Cultura Manchay. Solo hay un montículo con dos brazos que extiende de un montículo principal en nombre, y la parte central es más pequeña que ambos brazos (figura 5). Al montículo le falta un eje central porque el brazo izquierdo curva al sureste. El relleno del montículo también es atípico para un templo en planta de $\langle U\rangle$. Se consiste en una capa de derrito; no hay evidencia de varios eventos constructivos o renovaciones. El derrito no es normal para un templo en planta de $<\mathrm{U}>\mathrm{y}$ contiene restos botánicos, restos malacológicos, piedras quemadas, y cerámica que incluye fragmentos diagnósticos

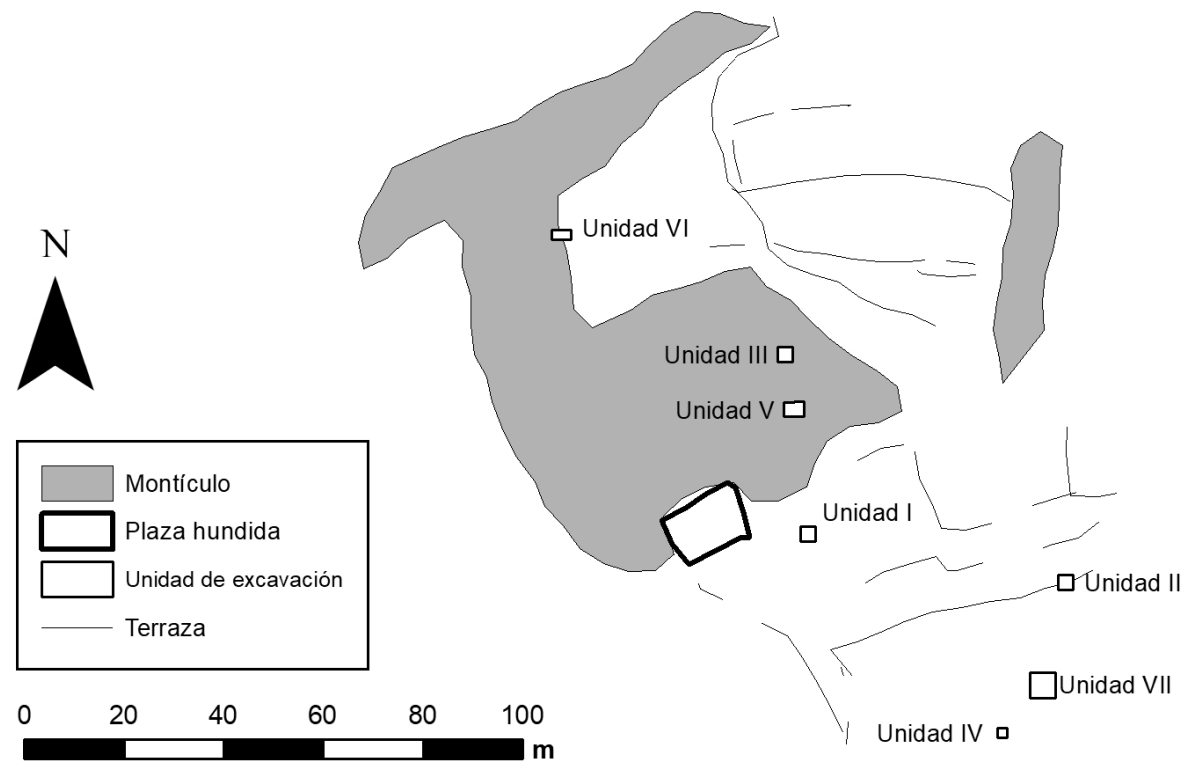

Figura 5. Mapa de Anchucaya. 
del Horizonte Tardío. Es muy probable que el montículo fue construido como un producto de la creación las terrazas agrícolas.

La construcción de las terrazas dañaba muchos de los contextos que corresponden a la ocupación del Periodo Inicial. Las terrazas estaban hechas por la renovación de tierra incluyendo los estratos que representan ocupaciones anteriores (figura 6; Milan 2019). Solo hay tres unidades de excavación que contiene contextos que fechan al Periodo Inicial. Unidad II, que se ubica cerca la ladera este de la quebrada, tiene una capa que representa un depósito funerario. Unidad IV se ubica adentro de una estructura del Horizonte Tardío encima de una terraza natural. Las capas más profundas conservan restos del Periodo Inicial. Unidad VII estaba excavado al este de la Unidad IV y tiene pocos materiales de la ocupación temprano.

Unidad IV tiene la evidencia más clara de una ocupación del Periodo Inicial. Se excavó un pozo de dos metros por dos metros con cuatro capas encima de tierra estéril. Las Capas A y B se fechan al Periodo Intermedio Tardío y Horizonte Tardío. Debajo de ellos, las Capas C y D son más antiguos. Muestras de carbón recuperadas de las dos capas fechan entre 1550 y 1300 a. C., que corresponde a la Fase Río en Malpaso (Tabla 1). Aunque no hay rasgos de arquitectura residencial, se recupera-

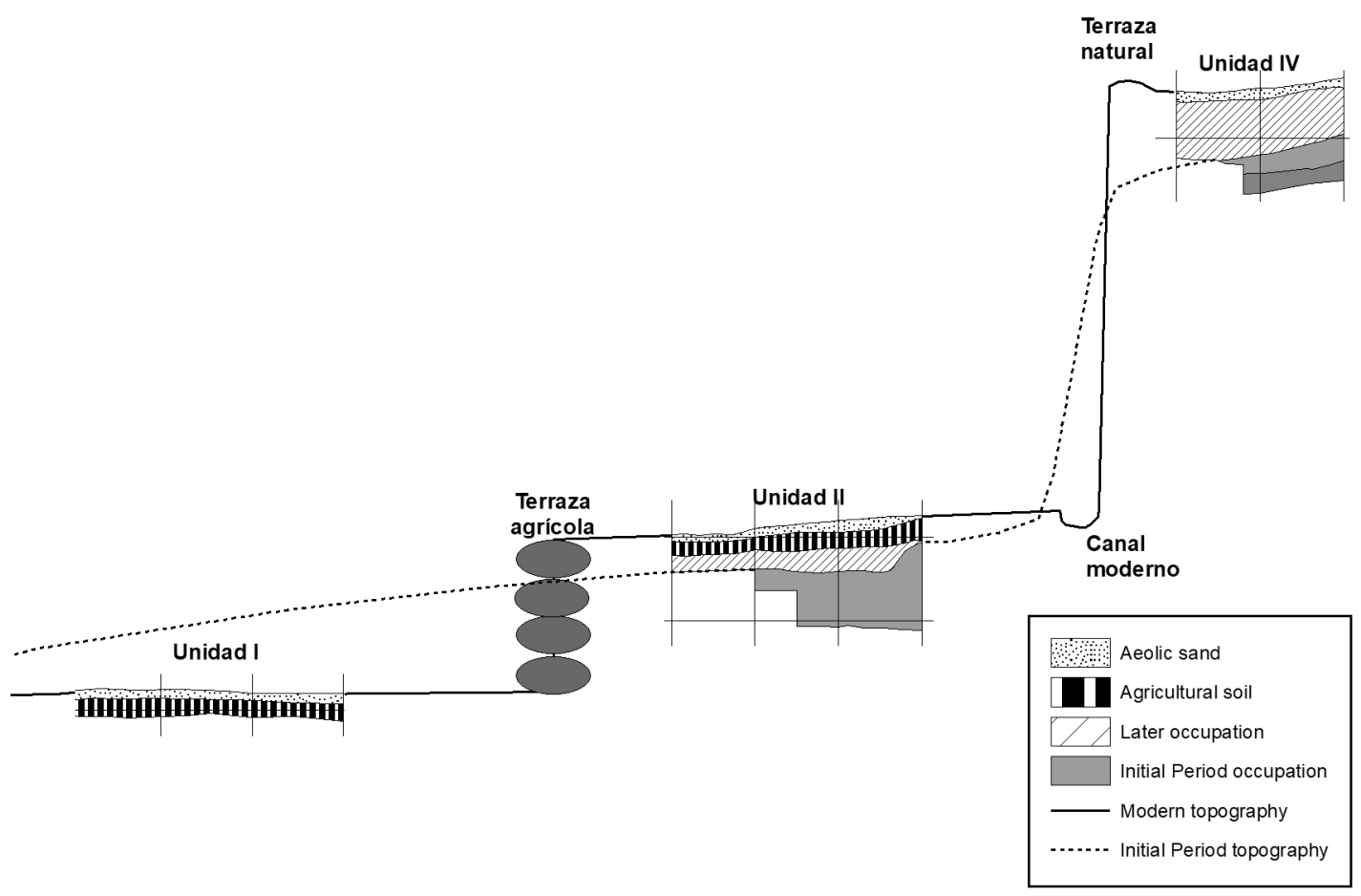

Figura 6. Dibujo transversal de Anchucaya con perfiles para presentar el efecto de las terrazas sobre la tafonomía del sitio. 
ron restos malacológicos, huesos de animales quemados, unos cristales de cuarzo, y cerámica típica del Periodo Inicial.

La Unidad VII es más cercano a la ladera de la quebrada. Como en la Unidad IV, las capas A y B corresponden a la ocupación tardía del sitio. La Capa C es un depósito de piedra encima de la tierra estéril. Esta capa contiene una cantidad de restos malacológicos, cristales de cuarzo, y cerámica temprana. El material es similar al que se encuentra en la Unidad II. Tampoco hay contextos residenciales en la Unidad VII, pero se encontraron los rasgos de un piso en el perfil norte.

Unidad II también se ubica cerca la ladera de la quebrada y encima de la terraza agrícola más alta. La Capa A es una arena eólica y Capa B representa la formación de una tierra agrícola con canales de riego y las raíces de plantas de maíz. Similar a la Unidad VII, Capa C es un depósito rocoso con una mezcla de cerámica, restos malacológicos, y cristales de cuarzo. También contiene los restos de un mínimo de nueve individuos incluyendo cinco adultos, un adolescente, dos niños, y un infante. Los huesos son rotos y desarticulados, entonces no es posible recuperar más información sobre la población de Anchucaya. La conservación de los huesos indica que la capa se formó por un caído de piedras; originalmente los restos humanos estaban enterrados encima de la cresta que forma la ladera de la quebrada. Basado en el material que se recupera de esta capa, el caído probablemente ocurrió entre el Horizonte Temprano y el Periodo Intermedio Temprano (entre 500 y 200 a. C.)

Tabla 2. Distribución de temperantes usado en la cerámica del valle medio de Lurín.

\begin{tabular}{|c|c|c|c|c|c|c|c|c|c|}
\hline \multirow[t]{3}{*}{ Sitio } & \multirow{3}{*}{$\begin{array}{c}\text { Total } \\
\text { fragmentos } \\
\text { analizados }\end{array}$} & \multicolumn{8}{|c|}{ Temperante } \\
\hline & & \multicolumn{2}{|c|}{ Arena } & \multicolumn{2}{|c|}{ Cuarcita } & \multicolumn{2}{|c|}{ Mica } & \multicolumn{2}{|c|}{ Otro material } \\
\hline & & Cantidad & $\%$ & Cantidad & $\%$ & Cantidad & $\%$ & Cantidad & $\%$ \\
\hline $\begin{array}{l}\text { Malpaso - } \\
\text { Fase Río }\end{array}$ & 213 & 82 & $38.5 \%$ & 53 & $24.9 \%$ & 77 & $36.2 \%$ & 1 & $0.5 \%$ \\
\hline $\begin{array}{l}\text { Malpaso - } \\
\text { Fase Liza }\end{array}$ & 1405 & 889 & $63.3 \%$ & 427 & $30.4 \%$ & 68 & $4.8 \%$ & 21 & $1.5 \%$ \\
\hline $\begin{array}{l}\text { Malpaso - } \\
\text { Fase Milagro }\end{array}$ & 319 & 194 & $60.8 \%$ & 71 & $22.3 \%$ & 38 & $11.9 \%$ & 16 & $5.0 \%$ \\
\hline $\begin{array}{l}\text { Anchucaya - } \\
\text { Todo el sitio }\end{array}$ & 256 & 179 & $69.9 \%$ & 48 & $18.8 \%$ & 22 & $8.6 \%$ & 7 & $2.7 \%$ \\
\hline $\begin{array}{l}\text { Anchucaya } \\
\text { - Contextos } \\
\text { tempranos }\end{array}$ & 104 & 64 & $61.5 \%$ & 19 & $18.3 \%$ & 19 & $18.3 \%$ & 2 & $1.9 \%$ \\
\hline Chillaco & 815 & 208 & $25.5 \%$ & 573 & $70.3 \%$ & 14 & $1.7 \%$ & 20 & $2.5 \%$ \\
\hline
\end{tabular}


Por el daño del caído es difícil determinar mucho sobre la población de Anchucaya, los materiales recuperados revelan datos sobre los ritos funerarios del sitio. Con los restos humanos se encuentran grandes cantidades de cerámica decorada y cristales de cuarzos. Cristales de cuarzo están encontrados en contextos residenciales en varios sitios en el valle medio de Lurín. También se encuentran algunos cristales en el brazo izquierdo de Malpaso. Cristales son típicos de contextos rituales en sitios del Periodo Inicial y Horizonte Temprano. La cantidad de cristales encontrada en Unidad II de Anchucaya es más grande que en otros contextos, y significa que la población de Anchucaya realizaban sus propios ritos funerarios.

La cerámica encontrada con los restos humanos y en otros contextos formativos es característica del Periodo Inicial. La mayoría son mal cocida, sin decoración, y tiene arena o mica para temperante. Arena era el temperante más usado en Anchucaya, encontrado en más de $60 \%$ de la cerámica analizada en contextos formativos. Los otros temperantes comunes durante este periodo son mica y cuarcita molida (Tabla 2). La frecuencia de los temperantes usados en Anchucaya era similar a los que se encuentra en contextos de la Fase Río en Malpaso, y significa que los dos sitios compartían una tradición de preparar cerámica.

La vasija más común en Anchucaya es la olla sin cuello. Los bordes de las ollas varían bastante, pero lo más típico es en la forma de una coma (figuras 7-1 a 7-4). El borde es grueso e invertido, pero no se forma en una manera consistente. La mayoría de las cuencas encontradas tienen paredes rectas y bordes cónicos, similar a los que encuentran en Malpaso en la Fase Río (figuras 7-5 a 7-8).

También la cerámica decorada de Anchucaya es comparable a la cerámica de Malpaso durante la Fase Río. En ambos sitios la decoración más común es un diseño sencillo inciso en la superficie de la vasija (figuras 7-6 a 7-9). También, círculos estampados están usados (figuras 7-7 y 7-8), pero no se encuentra ejemplos de puntación zonal. Las similitudes en la decoración entre la aldea y templo otra vez indican que las poblaciones de los dos sitios compartían una tradición de preparar cerámica.

Anchucaya tenía una relación complicada con su centro cívico-ceremonial más cercano. Por un lado, Anchucaya era autónoma. La comunidad podía manejar sus propias chacras, manufacturaban sus propios bienes, y realizaron rituales religiosos en la aldea misma. Por otro lado, Anchucaya existía por Malpaso; los templos en planta de $<\mathrm{U}>$ estaban conectados al desarrollo de las tecnologías esenciales para fundar Anchucaya. También, la cerámica entre los dos sitios indica que había lazos entre las dos comunidades. Mientras la población de Anchucaya producían su proprios cerámicos, compartían una tradición con la gente de Malpaso. Malpaso también conectó la población de Anchucaya a otros partes del valle Lurín. La presencia de restos malacológicos indica que la gente de Anchucaya tenía acceso a recursos marinos de la costa del Pacífico. Igualmente, Anchucaya podía exportar recursos de la chaupiyunga a la chala. 


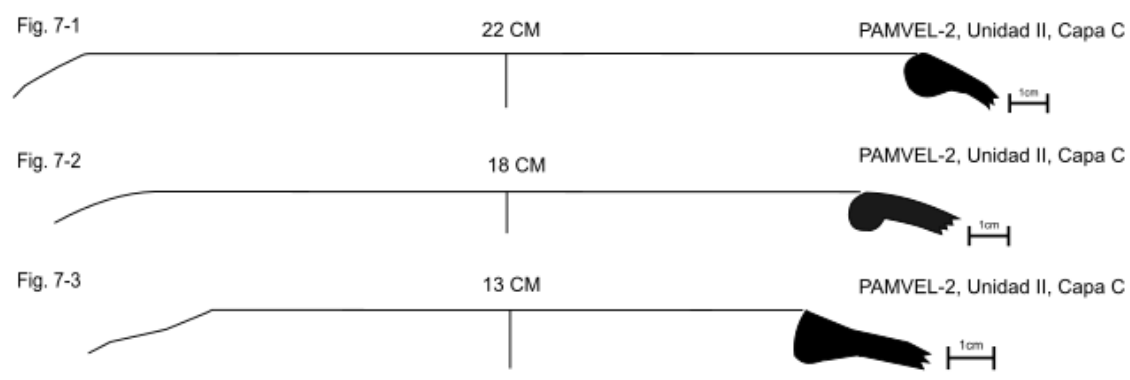

Fig. 7-4

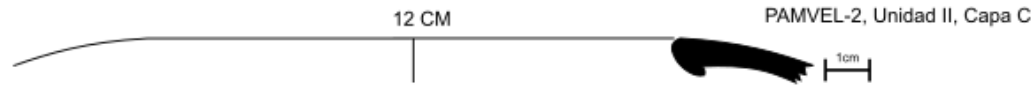

Fig., 7-5

$22 \mathrm{CM}$

PAMVEL-2, Unidad II, Capa C
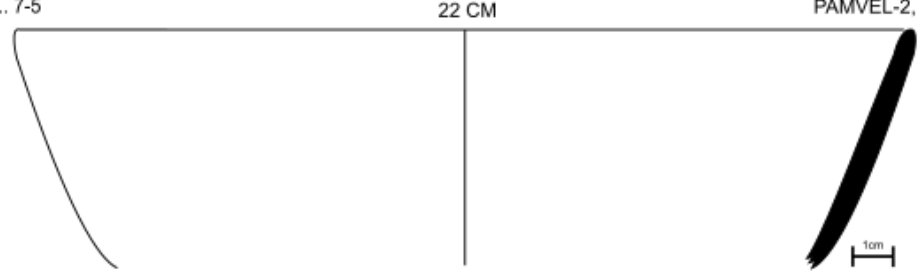

Fig 7-6

$20 \mathrm{CM}$

PAMVEL-2, Unidad III, Capa A
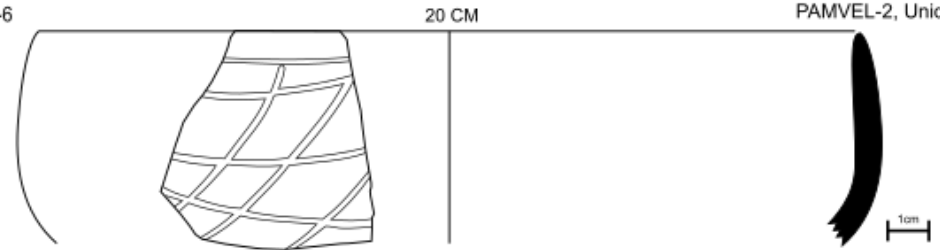

Fig. 7-7

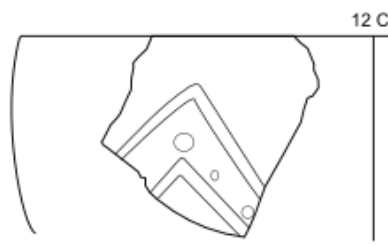

PAMVEL-2, Unidad II, Capa B

$\mathrm{CM}$
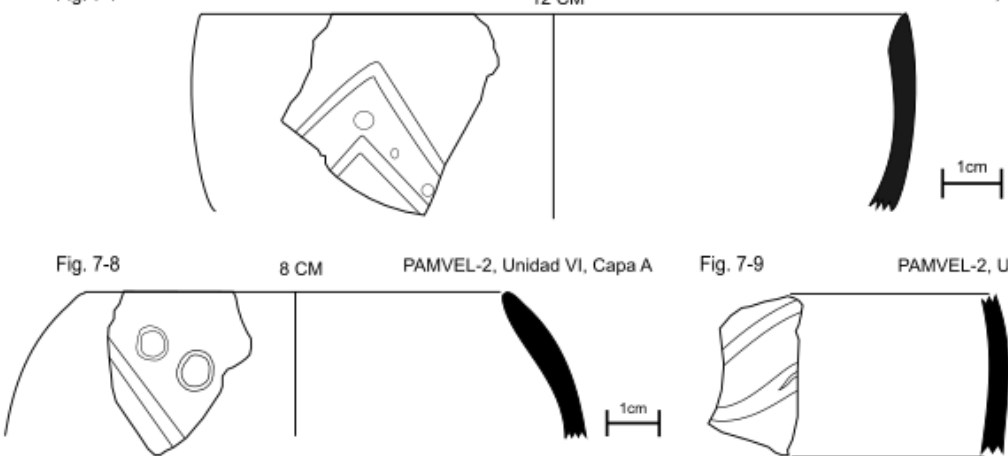

Fig. 7-9

PAMVEL-2, Unidad II, Capa C

Figura 7. Dibujos de cerámica de Anchucaya. 


\section{Chillaco}

En sus maneras Chillaco es el contrapunto a Anchucaya. Anchucaya era contemporánea con la Fase Río en Malpaso y la ocupación inicial del valle medio de Lurín. Al contrario, la ocupación de Chillaco corresponde con la Fase Milagro u ocupación terminal de Malpaso. Como se ha visto en la sección anterior, la cultura material de Anchucaya es similar a la que se encuentra en Malpaso y otros sitios de la Cultura Manchay. Los materiales recuperados en Chillaco sugieren que la población del sitio tenía más en común con la gente que vivía en Huarochirí. Entonces Chillaco contrasta con Anchucaya para mostrar como la sociedad compleja desarrolló por el Periodo Inicial. Aún más, se muestra como los centros cívicos-ceremoniales unían poblaciones diversas.

Chillaco se ubica 55 kilómetros del océano Pacífico y más de 20 kilómetros de Malpaso. Está en la base de una montaña (1200 m s. n. m.) al margen sur del valle y justo al este de una quebrada. Hay un pueblo moderno del mismo nombre, y ahora usan el sitio arqueológico como una chacra de tuna para la crianza de cochinillas. Mientras la tafonomía de Anchucaya es el producto de sus varias ocupaciones, Chillaco se formó por un evento cataclísmico. Después del abandono del sitio había un caído que enterró todo el sitio en una capa de piedra suelta.

Por eso el sitio tiene una estratigrafía uniforme. La Capa A es el producto de este caído y consiste en piedra suelta con artefactos. El grosor de esta capa varia. Cerca de la ladera de la montaña Capa A tiene una profundidad de un metro y medio, pero al margen del sitio solo es medio metro. La mayoría de los artefactos recuperados de Chillaco son de Capa A, incluyendo cerámica, restos botánicos, restos faunos, y restos malacológicos. La Capa B es un tierra arcillosa y amarilla; aunque no tiene muchos artefactos toda la arquitectura del sitio está asociada con esta capa. La única muestra de carbón recuperado de Chillaco proviene de un muro de pirca en Unidad VII (figura 8). Se fecha alrededor 900 a. C., la transición entre el Periodo Inicial y Horizonte Temprano y cuando los templos en planta de $<U>$ en el valle bajo se abandonaron (Tabla 1). La capa C es tierra estéril.

La arquitectura residencial de Chillaco consiste en una serie de conjuntos, o conglomeraciones de estructuras. Las estructuras fueron hechas de pirca y tienen una forma circular; fueron semihundidas y no hay evidencia que tenían pisos (figuras $8 \mathrm{y}$ 9). Un conjunto consiste en un grupo de hasta nueve estructuras de varios tamaños. La estructura más grande tenía un diámetro de 15 metros y la más pequeña solo uno metro y medio (Scheele, 1970, p. 201). Los tamaños diferentes pueden indicar usos diferentes. Las más grandes podían servir como viviendas y las más pequeñas para almacenaje (Flannery, 2002, p. 424). Excavaciones en Chillaco en 2010 no encontra- 

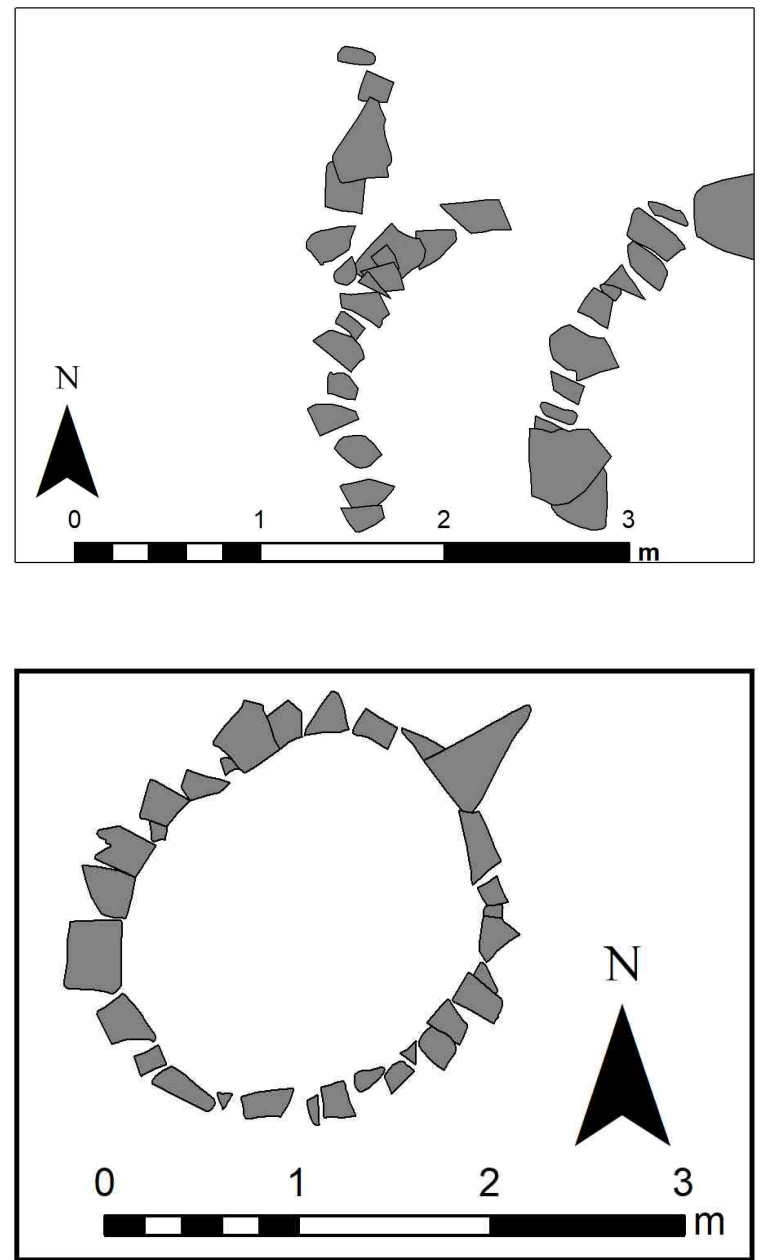

Figura 8. Ejemplo de una estructura circular de Chillaco, Unidad IX.
Figura 9. Muros de pirca de estructuras circulares de Chillaco, Unidad VII.

ron conjuntos completos, solo estructuras. El sitio de Palma, 5 kilómetros al este de Chillaco presenta una vista de algunos conjuntos intactos (figura 10).

Esta forma de arquitectura residencial es distinta a la que se encuentra en las zonas residenciales en los templos en planta de $<U>$. Casas excavadas detrás de los montículos principales en Cardal, Malpaso, y Mina Perdida consistían en estructuras cuadrículas hechos de adobes o piedras con mortero. Normalmente las estructuras tenían pisos estampados y techos de quincha. Conjuntos de estructuras circulares son más típicos de la arquitectura residencial en la sierra. El ejemplo más notable es el sitio de Atalla en Huancavelica (Burger y Matos, 2002, p. 163). Es interesante a notar que hay dos sitios con arquitectura similar en el valle bajo de Lurín, Tablada de Lurín y Cerro Punta Blanca. Pero, ambos sitios son campos temporales que se usaban para explotar recursos locales (Jiménez, 2009). 
Una diferencia más entre Chillaco y otros sitios en el valle medio de Lurín es la ausencia de cristales de cuarzo. Se encuentra cuarzo en varios contextos en Malpaso, incluyendo en espacios rituales en el brazo izquierdo y contextos domésticos en la zona residencial. Como se ha mencionado en la sección anteriormente, la mayoría del cuarzo encontrado en Anchucaya está asociada con contextos funerarios. En todo el sitio de Chillaco, solo se encuentra dos cristales de cuarzo. La ausencia de cuarzo no es por la falta de contextos funerarios. Restos humanos están dispersos por el sitio, una consecuencia del caído que formó la Capa A, pero los cristales no están asociados con los huesos. Entonces la ausencia de cuarzo significa que la población de Chillaco realizaban ritos diferentes de los de la gente en otros partes del valle Lurín.

No es sorprendente que la cerámica de Chillaco tiene bastante diferencias de las de otros sitios en el valle medio de Lurín. La mayoría, más que 70\%, de la cerámica tiene cuarcita molda para temperante (Tabla 2). Arena era usada como temperante en $25 \%$ de la cerámica en Chillaco, y se encuentra mica en menos que $5 \%$. Es una diferencia grande en comparación a la cerámica de Malpaso y Anchucaya, donde arena era el temperante más común. La diferencia también es temporal, porque la cantidad de cerámica con cuarcita como un temperante en Malpaso aumenta sobre el tiempo.

Como en Malpaso y Anchucaya, las vasijas más comunes en Chillaco fueron ollas sin cuellos y cuencos, pero tienen formas diferentes. En los otros sitios, los bordes de

$$
\text { Conjunto } 4
$$

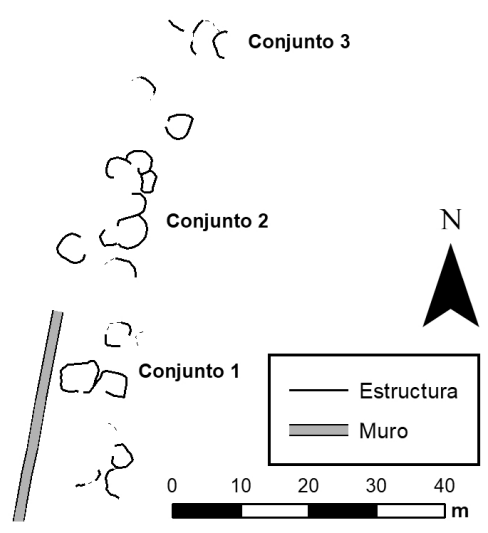

Figura 10. Mapa de Palma 
las ollas sin cuellos tienen la forma de una coma. En Chillaco el borde es más grueso, pero no se forma tan abrupto (figuras 11-1 a 11-3). Los cuencos de Chillaco típicamente tienen paredes curvadas con bordes más gruesos. Son parecidas a las ollas sin cuellos, pero con bocas menos restringidas (figuras 11-4 y 11-5).

Aunque la cerámica hecha en Chillaco es distinta, también hay fragmentos que parecen importados de los varios templos en planta de $<U>$ en el valle Lurín. Algunos fragmentos están decorados con pintura bícromo, donde la vasija tiene pintura roja y amarilla. Típicamente los colores están separados por una línea incisa en la superficie de la vasija. Este estilo de decoración se encuentra en Manchay Bajo y también en contextos de la Fase Milagro en Malpaso. También hay ejemplos de diseños intricas incisos como se encuentra en Cardal, puntación zonal (figuras 11-6, 11-7, y 11-9). Algunos fragmentos con puntación zonal tienen diseños en forma de hoja (figura 11-8). En Malpaso se encuentra este diseño con círculos estampados y tres puntos (figura 4-7 y 4-9). También se encuentra dos fragmentos decorados con el circulo con punto. Es muy probable que estos fragmentos fueron importados de otros sitios, y también posible que algunos cerámicos provienen de fuera del valle Lurín.

Los materiales indican que Chillaco estaba ocupada por una población que es distinta de las que ocupaban Malpaso y Anchucaya. Decisiones en cómo construir arquitectura residencial o preparar cerámica indican que la gente de Chillaco tenían más en común con la gente de que vivían en la sierra que la gente en el valle bajo. Pero no significan que la chaupiyunga se ocupaban por dos etnias diferentes, más que había dos poblaciones entrelazadas con dos formas de vivir distintas (Salomon et al 2011: 36). La gente que se afiliaban con la Cultura Manchay migró del valle bajo de Lurín a la chaupiyunga para explotar sus recursos y fundaron las comunidades de Malpaso y Anchucaya. Igualmente, gente que vivían en Huarochirí migró a la chaupiyunga y fundaron Chillaco. El resultado es que las dos poblaciones interactuaban y formaban una red que extiende por la costa central hasta la sierra adyacente. Tal vez Chillaco no se idéntica con la Cultura Manchay, pero por sus lazos con Malpaso tenía acceso a los bienes de otros sitios. Eso incluye los cerámicos de varios templos y recursos marinos.

\section{ANÁLISIS}

Anchucaya y Chillaco ofrecen vistas particulares al desarrollo de la sociedad compleja en la costa central del Perú. La aparición de arquitectura monumental durante el Periodo Inicial catalizó varios cambios a la sociedad andina. Pero los templos no ejercían un poder político substantivo o control sobre los asentamientos cercanos. Una aldea podía ser una comunidad autónoma que expresaba su identidad por la producción de una cultura material distinta. En los casos analizados se presentan dos identidades distintas. 


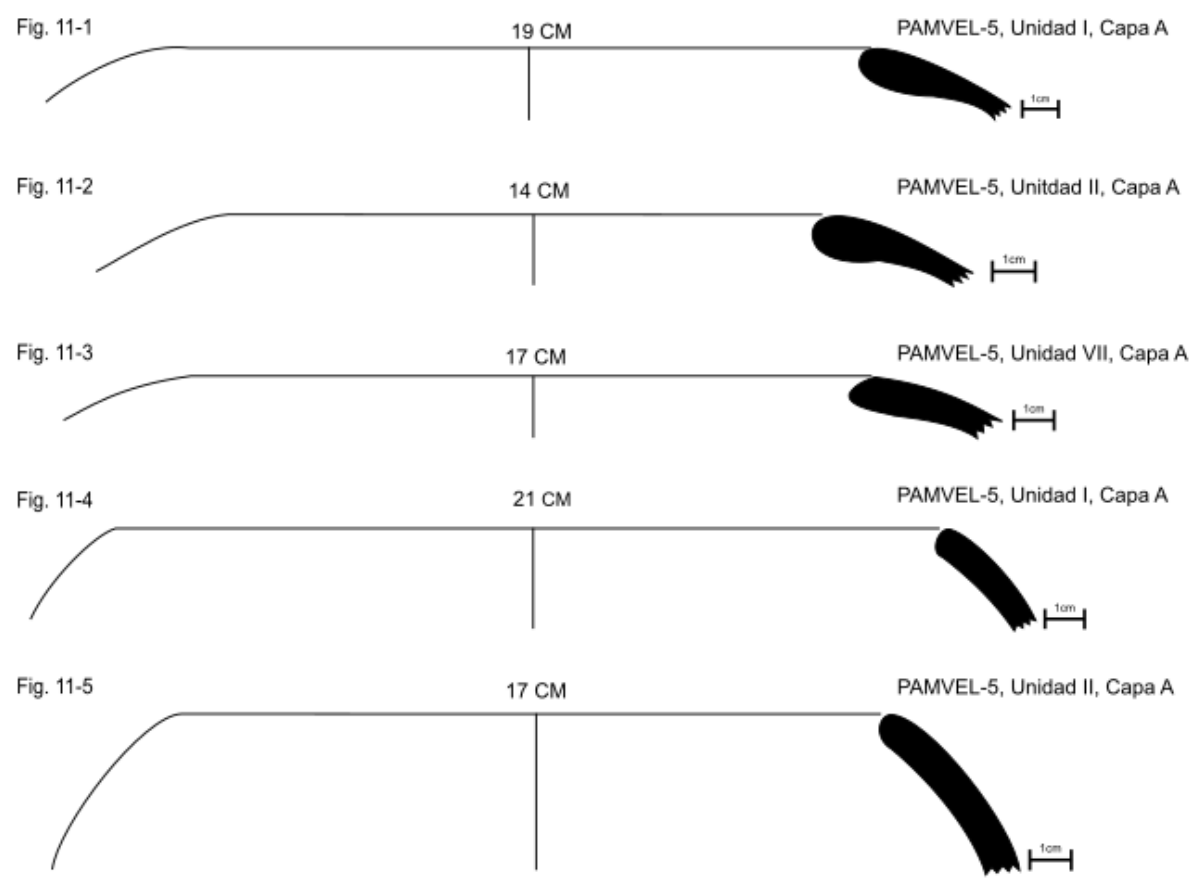

Fig. 11-6 PAMVEL-5, Unidad II, Capa A
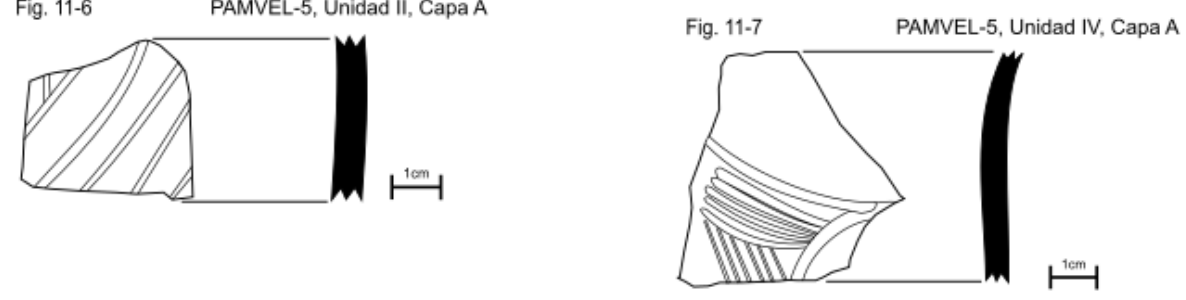

Fig. 11-8 PAMVEL-5, Unidad I, Capa A

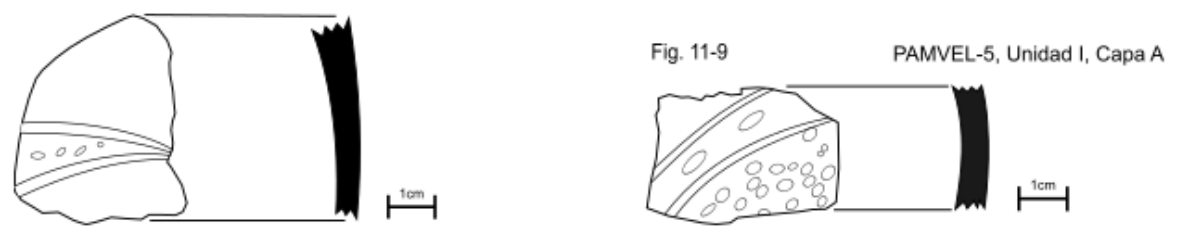

Figura 11. Dibujos de cerámica de Chillaco 
Las diferencias entre Anchucaya y Chillaco representan dos poblaciones que ocupaban el valle medio de Lurín. Anchucaya era más alineada con la Cultura Manchay y la población del valle bajo de Lurín, y Chillaco era más cercano a la población serrana que vivía en Huarochirí. Arquitectura residencial es una línea de evidencia para entender una diferencia. Paul Goldstein (2000: 183) explica como la forma de la arquitectura residencial puede ser un indicador de identidad etnia en la sierra sur del Perú en el Horizonte Medio. Es posible que la arquitectura residencial del valle medio de Lurín presenta una situación similar. Diferencias en la cerámica apoya esta interpretación. El uso de temperantes diferentes es una decisión que puede representar una identidad étnica o política (Livingood 2010: 65). En el caso del valle medio de Lurín, el uso de temperantes diferentes era una elección deliberada de un grupo de personas. Arena y cuarcita están igualmente abundante en el valle medio de Lurín. El uso de un temperante en particular no era por la falta de acceso a recursos más bien una tradición con una preferencia de materiales compartido entre un grupo.

También las diferencias entre las comunidades de Anchucaya y Chillaco reflejan relaciones diferentes con Malpaso. Anchucaya era más cercano al templo, y por eso los materiales recuperados son similares. La cerámica preparada en los dos sitios usa pastas similares, vasijas comparables, y decoraciones parecidas. Aunque hay una ausencia de arquitectura en Anchucaya había rasgos de un piso en un perfil de la Unidad VII. El piso es parte de la arquitectura residencial que se encuentra en los templos en planta de $\langle\mathrm{U}\rangle$. En contraste, no había ningún rasgo de un piso en las estructuras de Chillaco. A la misma vez, la comunidad de Anchucaya expresó su independencia. El ejemplo más significante es la presencia de cristales de cuarzo en contextos funerarios. La cantidad encontrada no tiene comparación en Malpaso e indica que Anchucaya realizaba sus propios ritos. Malpaso no tenía un monopolio sobre rituales religiosos. Por eso, Anchucaya podía ser un asentamiento afiliado con un templo en planta de $<\mathrm{U}>\mathrm{y}$ a la misma vez una comunidad independiente (ver Davis, 2011, p. 145).

Al contraste, no hay razón a creer que Chillaco estaba afiliado con Malpaso. Los materiales recuperados de la aldea son distintos en cada manera en comparación a los otros sitios en el valle medio de Lurín. En parte es porque Chillaco está lejos de los sitios asociados con la Cultura Manchay y no tenía contacto regular con otras comunidades. Pero Chillaco sí tenía contacto con Malpaso, y por este contacto estaba conectado a una red de intercambios amplias. Previamente se ha notado la presencia de cerámicos importados, y también se encuentra restos malacológicos en todas las unidades de excavación en el sitio. Eso indica que el consumo de mariscos era normal para la población de Chillaco si no la base de su dieta. La comunidad de Chillaco era diferente de las que se asociaban con la Cultura Manchay, pero estaban enlazados. 
Por otra parte, las diferencias entre los sitios son productos del hecho que los dos estaban ocupados en partes diferentes en el Periodo Inicial. Anchucaya era uno de los primeros asentamientos en el valle medio de Lurín, establecido poco después de Malpaso. Su fundación era parte de la migración de gente a la chaupiyunga del valle bajo de Lurín. Chillaco estaba ocupado al comienzo del Horizonte Temprano. Una red de intercambios ya existía en el valle Lurín durante del Periodo Inicial, y creció durante la Fase Milagro y conectó Malpaso y otros asentamientos con el resto de los Andes. Es natural que los desarrollos del Periodo Inicial crearon una sociedad más diversa.

Una similitud final entre los tres sitios descritos es que cada uno tenía evidencia de un caído de piedras cataclísmico. En cada sitio los contextos del Periodo Inicial están enterrados por una capa gruesa de piedra que contiene una cantidad de artefactos incluyendo cerámica decorada. Hay la posibilidad que estos depósitos son del mismo evento. Un terremoto grande en la costa central podía desestabilizar las laderas del valle de Lurín e instigar varios caídos. Si todos son el producto de un evento sísmico, se ocurrió después del abandono de Malpaso y Chillaco, pero antes de la ocupación Intermedio Temprano de Anchucaya.

\section{CONCLUSIÓN}

La comparación de Anchucaya y Chillaco ofrece una vista nueva al desarrollo de la sociedad compleja y el rol de arquitectura monumental en la costa central del Perú. Si no se enfoca en los centros cívicos-ceremoniales, las excavaciones de aldeas presentan las implicaciones más amplias de la aparición de la sociedad compleja en la costa central. Hay mucha gente que no vivía alrededor los templos en planta de $<U>$, y sus vidas estaban afectados por estos desarrollos.

En las últimas décadas los arqueólogos le están dando más importancia a las perspectivas de asentamientos pequeños en las sociedades complejas tempranas. Sus obras les presentan como comunidades autónomas que expresaban su independencia en varias formas (Davis 2011; Goldstein 2000; Ratto et al 2019; Sheets et al 2015). Aunque tenían lazos con un centro cívico-ceremonial, Anchucaya y Chillaco eran comunidades distintas con sus propias culturas materiales. La sociedad del Periodo Inicial consistió en varias comunidades diferentes que estaban conectados por una red social compleja.

Agradecimientos: Este artículo no sería posible sin el apoyo de Richard Burger y Lucy Salazar quienes me daban la inspiración para revisar el manuscrito. También gracias a Renee Milan por las revisiones al manuscrito en castellano. El artículo está dedicado a Martha Martin de Rossi. 


\section{REFERENCIAS BIBLIOGRÁFICAS}

Burger, R. (1992). Chavin and the Origins of Andean Civilization. Thames and Hudson: New York.

Burger, R. (2009). Los Fundamentos sociales de la arquitectura monumental del Periodo Inicial en el valle de Lurín, Richard Burger and Kryzstof Makowski (eds.). Arqueología del Periodo Formativo en la Cuenca Baja de Lurín (pp. 17-36). Lima, Peru: Fondo editorial PUCP.

Burger, R., and Matos, R. (2002). Atalla: A Center on the Periphery of the Chavín Horizon, Latin American Antiquity 13, pp. 153-177.

Burger, R. and Lucy Salazar. (1991). Recent Investigations at the Initial Period Center of Cardal, Lurín Valley. Journal of Field Archaeology 18, pp.275-296.

Burger, R. and Salazar, L. (1998). A Sacred Effigy from Mina Perdida and the Unseen Ceremonies of the Peruvian Formative, Res 33, pp. 28-53.

Burger, R. and Salazar, L. (2008). The Manchay Culture and the Coastal Inspiration for Highland Chavín Civilization, Chavin: Art, Architecture and Culture (pp. 85-105). William J Conklin and Jeffery Quilter (eds.). Los Angeles: Costen Institute of Archaeology.

Davis, A. (2011). Yuthu: Community and Ritual in an Early Andean Village. Ann Arbor: University of Michigan Press

Fajardo, F. (1996). Centro Cívico Ceremonial de Piedra Lisa, Implicancias Durante el Formativo Medio. Gori Echevarria (ed.). La Universidad Nacional Mayor de San Marcos y el VI Congreso Nacional de Estudiantes de Arqueología Lima: Facultad de ciencias sociales, Universidad Mayor de San Marcos

Flannery, K. (2002). The Origins of the Village Revisited: From Nuclear to Extended Households. American Antiquity 67, pp. 417-433.

Goldstein, P. (2000). Communities without Borders: the Vertical Archipelago and Diaspora Communities in the Southern Andes. In The Archaeology of Communities: A New World Perspective. Marcello A. Canuto and Jason Yaeger (ed.). Routledge: New York. pp. 182-209.

Jiménez, M. (2009). Ocupaciones tempranas de lomas en el valle de Lurín, Arqueología del Periodo Formativo en la Cuenca Baja de Lurín. Richard Burger and Kryzstof Makowski (eds.). Lima, Perú: Fondo editorial PUCP. pp. 182-209.

Livingood, P. (2010). Mississippian Polity and Politics on the Gulf Coastal Plain: A View from the Pearl River, Mississippi. Tuscaloosa: University of Alabama Press 
Mesia, C. (2000). Anchucaya: Aproximación Teórica Sobre un Complejo con Planta en U en el Valle Medio del Río Lurín, Arqueológicas 24, 45-52

Milan, C. (2014). The Initial Period (1800 - 800 BC) Occupation of the Middle Lurín Valley: A Discussion on the Interactions between Early Civic-Ceremonial Centers On the Central Coast of Peru and Nearby Hamlets. Unpublished dissertation, Yale University, New Haven

Milan, C. (2019). The Problem with Anchucaya: Site Formation Processes and Their Effect on Initial Period and Early Horizon Sites in the Central Andes, New Perspectives on Early Andean Civilization: Interaction, Authority, and Socioeconomic Organization during the 1st and 2nd Millennia B.C., Richard Burger, Yuji Seki and Lucy Salazar (eds.).

Patterson, T. (1985). The Huaca La Florida, Rímac Valley, Peru, Early Ceremonial Architecture in the Andes (pp. 59-69). Christopher Donnan (ed.). Washington DC: Dumbarton Oaks.

Pulgar Vidal, J. (1981). Geografía del Perú: Las ochos regiones naturales del Perú. Editorial Universo: Lima

Ratto, N., Néstor B. and Osella, A. (2019). Arquitectura de la aldea de Palo Blanco (ca. 0 1000 d. C), departamento de Tinogasta, Catamarca, Argentina, Latin American Antiquity 30 (4): 760-779

Salomon, F., Feltham, J. and Grosboll, S. (2011). La Revisita de Sisicaya, 1588: Huarochirí Veinte Años Antes de Dioses y Hombres. Fondo Editorial PUCP, Lima.

Scheele, H. (1970). The Chavin Occupation of the Central Coast of Peru. Harvard University: Unpublished Dissertation

Sheets, P., Christine, D., David, L., Rachel, E., Halmbacher A., Venicia Slotten, Rocío Herrera, Celine Lamb. (2015). "The Sociopolitical Economy of an Ancient Maya Village: Cerén and its Sacbe", Latin American Antiquity, 27(3), 235-258.

Silva, J. (1998). An Approach to the Formative Period in the Chillón Valley, Boletín de Arqueología PUCP 2. Perspectivas Regionales del Periodo Formativo en el Perú (pp. 251-268).

Stanish, Ch. (1999). Settlement Pattern Shifts and Political Ranking in the Lake Titicaca Basin, Peru. Settlement Pattern Studies in the Americas: Fifty Years since Viru. Brian Billman and Gary Feinman (eds.). Washington DC: Smithsonian Institution Press. pp. 116-28.

Thorne, P. (1999). Trade Networks in the Lurin Valley Initial Period. Paper presented at the Society of American Archaeology Annual Meeting. 
Williams, C. (1980). Complejos de Pirámides con Planta en U, Patrón Arquitectónico de la Costa Central, Revista del Museo Nacional 44, pp. 95-110.

\section{SOBRE EL AUTOR}

\section{Christopher Milan}

Bachiller de la Universidad DePaul University en 2004. Desarrolló su interés en la arqueología y los estudios Andinos. En el 2014 obtuvo el doctorado por la Universidad de Yale. Sus estudios se centran en la ocupación formativa de la costa central del Perú. Trabajó en el Departamento de Mapas de la biblioteca, Sterling Memorial Library de la Universidad de Yale. Allí desarrolló su interés en GIS.

Sus investigaciones abordan el alcance de la influencia de centros cívicos-ceremoniales y la autonomía de comunidades pequeñas. Toma como sitio de estudio la relación entre un templo en planta de $\langle\mathrm{U}\rangle$, Malpaso, y aldeas contemporáneas en el valle medio de Lurín.

Actualmente es docente universitario de antropología en la Universidad DePaul (Estados Unidos). 